\title{
Las cenizas del olvido y los medicamentos
}

\author{
YURI CARVAJAL ${ }^{(1)}$
}

En junio del año pasado, Carlos Alberto Vasallo -economista argentino y Profesor Titular de la Facultad de Bioquímica y Ciencias Biológicas (Universidad Nacional del Litoral), del Departamento de Economía de la Universidad de San Andrés y de Economía Sanitaria Universidad de Bologna (sede Buenos Aires)-, junto a Federico Tobar -Doctor en ciencias políticas y Director Ejecutivo de Salud y Fármacos- entregaron al Ministerio de Salud chileno el reporte "El mercado de medicamentos en Chile: caracterización y recomendaciones para la regulación económica". En el mes de junio de ese año se realizó una presentación y debate de sus propuestas y conclusiones. Por ahora, el documento permanece en el sitio web del Departamento de Economía de la Salud, en la sección publicaciones.

Pese a que el documento fue requerido con urgencia a partir de la necesidad de revisar la política nacional de medicamentos, tras el caso colusión de farmacias de cadenas salido a la luz pública en el 2009, las conclusiones y propuestas de este reporte han sido escasamente debatidas y el olvido amenaza con cubrir de cenizas tal esfuerzo.

Amenaza doblemente oscura, pues estudios independientes acerca de medicamentos no están fácilmente disponibles. Las cifras y propuestas en circulación proceden mayoritariamente de la industria o del comercio. La voz de los salubristas ha sido débil. Y los consumidores, considerados sólo en estudios provenientes del sector público: la encuesta de gasto en salud el 2007 y algunos estudios del Servicio Nacional del Consumidor (Sernac). Y ya sabemos que organizaciones de consumidores como Health consumers no han tenido éxito local en promover espacios públicos no estatales en materia de medicamentos.

Pero, además, porque este informe no se limita a abordar la colusión, sino que organiza una visión general de la industria, el mercado y el acceso. $\mathrm{Y}$ dado que contiene propuestas pensadas en su viabilidad inmediata, se hace más necesario desempolvarlo de olvido y volverlo presente.

Pese a estas consideraciones, al documento le pesan algunas de las dificultades del abordaje de medicamentos desde salud pública, que todos hemos padecido.

La más notable de ellas tiene que ver con el gran atraso existente en salud pública respecto de las estadísticas vinculadas a medicamentos. Una estimación tan sencilla como la magnitud del sector en el ingreso nacional, sigue siendo un guarismo casi pitagórico. El trabajo de cuentas satelitales de salud no logró incorporar las cifras de gasto privado, que son tan relevantes en esta materia. Asimismo, el manejo de la canasta de bienes y servicios de salud y de medicamentos en el cálculo del índice de precios al consumidor, requiere de un sustancial apoyo desde la clínica y la salud pública. La necesidad de usar reglas estándares como Anatomical, Therapeutic, Chemical classification system (ATC) y dosis diaria definida (DDD), exigencias oficiales de la OCDE incumplidas por Chile.

De no avanzar sustancialmente en esos desafíos, seguiremos siendo tributarios en nuestro análisis epidemiológico de las cifras privadas, construidas con otros propósitos, con otras sintácticas y otras semánticas.

(1) Escuela de Salud Pública. Facultad de Medicina. Universidad de Chile. Independencia 939. Santiago. Chile. ycarvajal@med.uchile.cl 
Del mismo modo como las estadísticas vitales han sido asumidas por una coordinación tripartita, las estadísticas de medicamentos requieren una vinculación entre el Instituto $\mathrm{Na}$ cional de Estadística (INE), el Departamento de Estadísticas e información en Salud (Deis) $\mathrm{y}$, quizás, dada la fuerte dependencia del comercio exterior, el propio Banco Central.

En un plano más inmediato, el uso de la Encuesta de Presupuestos Familiares (EPF) para caracterizar el consumo de medicamentos también sería de notable utilidad.

Pese a estas limitaciones y de regreso al documento, el informe de Vasallo identifica los puntos nodales de la condición de la venta de medicamentos en Chile. Un sector monopólico, con integración vertical, que ha hecho uso de esas condiciones privilegiadas para dominar el mercado. Respecto de la producción, de la organización de la industria, el rol de las patentes, el informe es mucho más escueto $\mathrm{y}$, quizás como lectura crítica del mismo, la óptica de la colusión organiza excesivamente el estudio e informa sus conclusiones.

El documento aborda la fragilidad de la industria nacional, la debilidad en la implementación de buenas prácticas de manufactura y como contrapartida, la desatención del Estado respecto de sus responsabilidades en estas materias, tanto en la dimensión regulatoria como en la provisión. El informe reafirma que el gasto de bolsillo y el precio de medicamentos son una fuente de desigualdad en el acceso a tratamiento. Que los seguros de salud, por sí mismos fuentes de inequidades, excluyan la cobertura de medicamentos entre sus servicios, es un elemento que profundiza y agrava esas desigualdades.

Por lo mismo, aunque es real la urgencia de contar con una Política Nacional de Medicamentos como el documento acierta en insistir y dentro de ella, el necesario impulso a los genéricos y algunas estrategias de control de precios, la carencia de una política protectora respecto de patentes, debilita el horizonte de mediano plazo para esa perspectiva. Materia respecto a la cual la acreditación de bioequivalencia no es panacea.

Más allá del enfoque hacia las barreras monetarias, existe la necesidad imperiosa de contar con información confiable e independiente respecto de medicamentos. No sólo se requiere, como acertadamente señala el documento, documentos oficiales y listados sino estrategias de comunicación que hagan de tal información, recursos efectivamente utilizables por las personas. A la publicidad de medicamentos existentes, que hace ya tiempo sobrepasó normas y prohibiciones, es necesario contraponer una publicidad oficial de uso adecuado. Campañas de factura tan novedosas y atractivas como las que realiza la industria. Si una información así no es financiada por el Estado, seguiremos en manos de la publicidad de laboratorios y farmacias, como estamos hoy.

El estudio y comunicación del reporte, así como la insistencia para que la actual Anamed asuma como su responsabilidad intelectual el seguimiento de los problemas reseñados, siguen representando tareas pendientes en la salud pública nacional. 